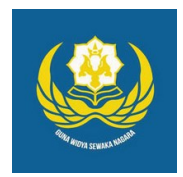

Jurnal Analogi Hukum

Journal Homepage: https://ejournal.warmadewa.ac.id/index.php/analogihukum

\title{
Implementasi Program Corporate Social Responsibility (CSR) Pada Pt. Furama Villa And Spa Ubud
}

\author{
I Gusti Ngurah Agung *, I Nyoman Putu Budiartha dan Ni Made Sukaryati Karma \\ Fakultas Hukum, Universitas Warmadewa, Denpasar, Bali-Indonesia \\ *prandiva.smapta@gmail.com
}

\begin{abstract}
How To Cite:
Agung, I, G, N., Budiartha, I, N, P., Karma, N, M, S. (2020). Implementasi Program Corporate Social Responsibility (CSR) Pada Pt. Furama Villa And Spa Ubud. Jurnal Analogi Hukum. 2(1). 53-58. Doi: http://dx.doi.org/10.22225/.2.1.1617.53-58
\end{abstract}

\begin{abstract}
Corporate social responsibility activities or other terms called CSR are corporate obligations where companies are required to be responsible for operational activities in the field of natural resources; CSR is regulated in article 74 of Law No. 40 of 2007 of the Company Law concerning social and environmental responsibilities. In the hotel and service operational activities of PT. Furama Villa and Spa Ubud, located in the village of Mekar Bhuana, Banjar Bindu, Badung certainly has a positive and negative impact on the economic, social, cultural and environmental aspects. As for the discussion to be discussed, among others; 1 . What is the CSR Program at PT. Furama Villa and Spa Ubud, 2. What are the Implications in the CSR Program at PT Furama Villa and Spa Ubud. This research is an empirical research which is analyzed qualitatively descriptive. Data obtained through interviews with parties involved in CSR activities. Implementation of CSR at PT. Furama has been committed to giving donations to people with disabilities, elementary school scholarships that have ranked I to $V$ and preserving nature by making agro farms. In its implications, the implementation of CSR in companies arises from several aspects, namely: the economy opens up employment opportunities while increasing people's living standards, socially creates positive emotions of the community and companies, and environmentally participates in preserving nature by planting trees and making agro farm.
\end{abstract}

Keywords: CSR, Villa, Tourism

\begin{abstract}
Abstrak-Kegiatan tanggung jawab social perusahaan atau istilah lainnya disebut CSR merupakan kewajiban perusahaan dimana perusahaan dituntut untuk bertanggung jawab atas aktivitas oprasional yang kegiatannya di bidang sumber daya alam, CSR diatur dalam pasal 74 Undang-Undang Nomor 40 tahun 2007 UUPT tentang tanggung jawab sosial dan lingkungan. Di dalam Kegiatan oprasional hotel maupun jasa PT. Furama Villa and Spa Ubud yang berlokasi di Desa Mekar Bhuana, Banjar Bindu, Badung tentu menimbulkan dampak positif dan negatif dalam sektor ekonomi, sosial budaya, lingkungan sekitar. Adapun pembahasan yang akan dibahas antara lain ; 1. Bagaimanakah Program CSR pada PT.Furama Villa and spa Ubud, 2. Bagaimanakah Implikasi dalam Program CSR pada PT Furama Villa and Spa ubud. Penelitian ini merupakan penelitian Empiris yang dianalisis secara kualitatif deskriptif. Data yang diperoleh melalui wawancara dengan pihak yang terlibat dalam kegiatan CSR. Adapun penerapan CSR pada PT. Furama sudah dilakukan berkomitmen dengan dilakukannya pemberian sumbangan terhadap penyandang cacat, beasiswa SD yang berprestasi peringkat I sampai $\mathrm{V}$ dan melestarikan alam dengan membuat agrofarm. Dalam implikasinya penerapan CSR dalam perusahaan timbul dari beberapa aspek yaitu; ekonomi membuka lapangan pekerjaan sekaligus meningkatkan taraf hidup masyarakat, sosial terjalinnya emosi positif masyarakat dan perusahaan, lingkungan ikut serta menjaga kelestarian alam dengan menanam pohon dan membuat agrofam.
\end{abstract}

Kata Kunci: CSR, Villa, Pariwisata

\section{Pendahuluan}

Konsep tanggung jawab sosial perusahaan bukan merupakan hal yang baru. Jauh sebelum adanya Undang-Undang Nomor 40 Tahun 2007 tentang Perseroan Terbatas (selanjutnya disebut
UUPT), pada masa Orde Baru pemerintah telah mengupayakan untuk meregulasi konsep tanggung jawab social perusahaan. Bahkan apabila diperhatikan isi dari pasal 33 UndangUndang Dasar 1945 Negara Republik Indonesia (selanjutnya disebut UUD NRI 1945) 
sebenarnya adalah aturan dasar untuk melaksanakan tanggung jawab sosial di Indonesia. Dikatakan demikian, karena berdasarkan ketentuan Pasal 33 UUD NRI 1945 terdapat prinsip dan pembangunan berkelanjutan, yaitu segala sumber daya alam dipergunakan untuk sebesar-besarnya kemakmuran rakyat. Dengan Pasal 33 UUD NRI 1945 ini juga kemuliaan manusia untuk menolong mereka yang tidak cukup berkemampuan produktif dengan melakukan kerelaan kedermawanan sebagaimana moralitas dan etika agama (Sriedhi Swasono, $2005: 15$ ).

Tanggung jawab sosial dan lingkungan perusahaan CSR sebelum masuk kedalam sistem hukum Indonesia, mulai diperkenalkan melalui pemikiran Howard R. Bowen yaitu menganai Social Responsibility of Businessman pada periode ini Howard R Bowen menulis bukunya pada saat dunia usaha belum mengenal korporasi maka istilah yang sering dignakan adalah tanggung jawab social social responsibility responsibility, social responsibility, dan businisman responsibility.

Bowen mendefinisikan social responsibility sebagai suatu kewajiban pengusaha dalam menjalankan kebijakan, keputusan atau tindakan dengan mengikuti nilai yang dianut oleh masyarakat (Saipulah dan Hasan, 2015 : 20-21). Kemudian pada akhir tahun 1990-an muncul definisi CSR oleh World Business Council for Sustainable Development sebagai lembaga forum bisnis di bawah Badan Perserikatan Bangsa-Bangsa. Adapun definisi CSR dimaknai sebagai komitmen bisnis untuk berprilaku etis, beroperasi secara legal dan berkontribusi terhadap pembangunan ekonomi sekaligus meningkatkan kualitas hidup karyawan dan keluarganya serta masyarakat lokal dan masyarakat secara umumnya (Rudito \& Famiola, 2013).

Di Indonesia, pengaruh terhadap isu mengenai tanggung jawab sosial dan lingkungan mulai dikenal masyarakat pelaku usaha pada tahun 1990. Saat itu, perusahaan secara umum memahaminya sebagai perbuatan yang memiliki maksud pemberian sumbangan kepada pihak-pihak yang membutuhkan, dan atau tanggung jawab sosial kepada lingkungan (Ika Tresna Setiani, 2015, Mengupas CSR dalam Konsep dan Sejarah, http:/ pride.co.id/2015/01/mengupas-csr-dalam-

konsep-dan-sejarah/ diakses 22 september 2018). Pemberian sumbangan ini hanya sebatas pendermaan dari tujuan sebuah perusahaan agar dapat dikatakan telah berbuat baik dan terlihat lebih baik di masyarakat, dengan bahasa lainnya telah melakukan pencitraan yang bersifat positif.

Kesadaran akan pentingnya menjaga lingkungan sekitar serta berkontribusi dalam membantu meningkatkan perekonomian masyarakat merupakan bagian yang tak terpisahkan dari PT Furama. Sebagai sebuah Perusahaan dengan tingkat pendapatan yang besar tidak lantas PT Furama tutup mata akan permasalahan yang ada di masyarakat. PT Furama Villa and Spa Ubud bergerak di dalam sektor pariwisata oleh karena perkembangan pariwisata dan akomodasi pendukungnya yang pesat, tentu dapat menimbulkan dampak positif dan negatif. Dampak positif dapat timbul dari beberapa aspek, diantaranya dari segi ekonomi, social budaya serta lingkungan, seperti menciptakan lapangan pekerjaan,menambah wisatawan masyarakat tentang bagaimana bangsa dari berbagai dunia serta mendorong meningkatnya pendidikan dan masyarakat sekitar.Dari dampak positif yang diperoleh diatas tentu juga ada dampak negatif yang diakibatkan.Efek negatif yang timbul seperti pergeseran system nilai dalam moral, etika kepercayaan dan pergaulan dalam masyarakat, dan ada dampak yang terpenting terjadi kerusakan lingkungan seperti pencemaran air, tanah dan udara akibat kegiatan operasional hotel, Oleh karena itu dampak negatif tersebut harus dapat dikendalikan oleh menejemen hotel maupun pemerintah dengan sedini mungkin yang menggunakan CSR, yang dimana CSR merupakan sebuah komitmen berupa tanggung jawab sosial perusahaan terhadap lingkungan dimana perusahaan tersebut beroperasi.

CSR atau lebih dikenal sebagai tanggung jawab sosial perusahaan merupakan salah satu kegiatan wajib perusahaan dalam menjalani tanggung jawab sosial kepada masyarakat yang telah diatur dalam pasal 74 ayat (1) UUPT yang menyatakan bahwa Perseroan yang menjalankan kegiatan usahanya di bidang dan atau berkaitan dengan sumber daya alam wajib melaksanakan tanggung jawab social danlingkungan.

Selain kewajiban yang telah diatur oleh Undang-Undang dimana Program CSR atau tanggung jawab sosial ini merupakan kebijakan Peraturan Pemerintah pada pasal 3 ayat (2) No. 47 tahun 2012 tentang tanggung jawab sosial lingkungan yang menyatakan Kewajiban perusahaan yang dimaksud ayat (1) baik didalam perseroan maupun di luar perseroan.

Berdasarkan uraian latar belakang diatas penulis, beberapa permasalahan yang dibahas sebagai berikut: 
Bagamanakah penerapan CSR PT. Furama Villa and spa Ubud?, Bagaimanakah Implikasi dalam Program CSR pada PT. Furama Villa and spa Ubud?

\section{Metode}

Metode yang digunakan dalam penulisan skripsi ini yaitu metode yuridis empiris yaitu mengkaji ketentuan hukum yang berlaku serta apa yang terjadi di masyarakat dengan kata lain penelitian yang terjadi di masyarakat dengan maksud untuk mengetahui dan menemukan fakta.

Dalam pengumpulan data, sumber data yang penulis digunakan adalah :

Data primer, yaitu data yang diperoleh secara langsung dari sumber pertama yakni terkait dengan permasalahan yang akan dibahas. Sumber data yang diperoleh dari wawancara

Data Sekunder, yaitu data Hukum yang erat kaitannya dengan bahan hukum Primer dan dapat membantu menganalisa, memahami, menjelaskan data primer, antara lain : bukubuku, hasil penelitian, media cetak, kamuskamus ensliklopedia yang berkaitan dengan Program CSR dan tanggung jawab sosial perusahaan yang diatur dalam Undang-undang dan kaidah dasar yang bersifat mengikat.

Teknik data yang saya gunakan dalam penulisian penelitian ini yaitu:

Pengumpulan bahan data primer diperoleh dari sumber-sumber primer, yakni yang mengetahui tentang pembahasan yang dibahas, informasi dari tangan pertama atau responden (Wardiyanta, 2006). Dalam penelitian ini data primer adalah data utama yang berkaitan terhadap program CSR dalam implikasi dan penerapan yang dilakukan PT Furama Villa \& Spa. Data tersebut diperoleh dari wawancara dan observasi langsung yang dilakukan.

Pengumpulan data sekunder yaitu berupa norma, kaidah dasar dan peraturan yang berkaitan, yang bersifat mengikat seperti Undang-Undang yang berkaitan dengan Program Tanggung jawab social perusahaan. Data ini juga diperoleh melalui studi kepustakaan yang dilakukan dengan cara meneliti teori yang relevan dengan masalah penelitian ini misalnya jurnal, refrensi yang relevan. Data sekunder ini berupa dokumentasi internet atau web data-data yang di dapat oleh peneliti dari PT Furama Villa \& Spa.

\section{Hasil Penelitian dan Pembahasan}

Penerapan CSR PT. Furama Villa and Spa ubud

Corporate Social Responsibility yaitu suatu konsep atau perbuatan yang dilakukan oleh perusahaan karena memiliki rasa tanggung jawab suatu perusahaan terhadap sosial ataupun lingkungan sekitar yang dimana perusahaan tersebut berada. Seperti menjalankan suatu kegiatan yang bisa meningkatkan kesejahteraan masyarakat di sekitarnya dan menjaga lingkungan, memberikan beasiswa untuk anak yang kurang mampu dilingkungan perusahaan. Dana untuk memelihara fasilitas umum, sumbangan untuk pembangunan desa atau fasilitas yang berguna untuk masyarakat yang sifatnya sosial dan bermanfaat untuk masyarakat setempat.

Definisi CSR menurut Edi Suharto adalah "kepedulian perusahaan yang menyisihkan sebagian keuntungannya (profit) bagi kepentingan pembangunan manusia (people) dan lingkungan (planet) secara berkelanjutkan berdasarkan prosedur yang tepat dan professional". Sedangkan Wibisono, Corporate Social Responsibility (CSR) "Merupakan suatu komitmen berkelanjutan oleh dunia usaha untuk bertindak etis dan memberikan kontribusi kepada pengembangan ekonomi dari komunitas setempat ataupun masyarakat luas, bersaman dengan peningkatan taraf hidup pekerja beserta keluarganya" (Wardiyanta, 2006).

Kemudian Menurut Soeharto Prawikusumo tanggung jawab social adalah sebuah konsep yang luas yang berhubungan dengan kewajiban perusahaan atau organisasi dalam memaksimumkan impact positif terhadap masyarakatnya (Prawirokusumo, 2003). Tanggung jawab social para pelaku usaha dalam suatu peusahaan terdiri atas empat dimensi tanggug jawab yaitu ekonomi, hukum, etika dan Philanthropies. Dari perusahaan harus bertanggung jawab kepada para shareloder, karyawan dan masyarakat sekelilingnya dalam hal pendapatan karyawan dan tersedianya pekerjaan. Kedua tanggung jawab tersebut merupakan terjadinya tanggung jawab etika dan kegiatan Philantrhopies.

Definisi Perusahaan itu sendiri merupakan suatu pengertian ekonomi yang digunakan dalam Kitab Undang-Undang Hukum Dagang disingkat (KUHD), namun KUHD belum memberikan Penjelasan resmi Mengenai Perusahaan itu (Muhammad, 2002).

Pada umumnya orang berpendapat 
bahwa PT merupakan suatu bentuk perseroan yang didirikan untuk menjalankan suatu perusahaan dengan modal perseroan tertentu yang terbagi atas saham-saham, dimana para pemegang saham ikut serta dengan mengambil satu saham atau lebih dan melakukan perbuatanperbuatan hukum dibuat oleh nama bersama, dengan tidak bertanggung jawab sendiri untuk persetujuan-persetujuan perseroan itu (dengan tanggung jawab yang semata-mata terbatas pada modal yang mereka setorkan) (Soemitro, 1993).

\section{Berdasarkan}

Undang-Undang Perseroan terbatas No. 47 tahun 2012 dan Peraturan Pemerintah No. 47 tahun 2012 dan setiap persoroan selaku subjek hukum yang mejalani bisnis atau dimanapun perusahaan tersebut berada haruslah memiliki hubungan baik dan tanggung jawab sosial antara masyarakat dan lingkungan. Oleh karena peraturan pemerintah tersebut, I Ketut Sudiarta selaku Human Resources Manager menerangkan tentang pandangan dan kebijakan Furama Villa \& Spa terhadap CSR pada tanggal 1 november 2018 menyatakan pandangan beliau sebagai berikut; CSR sangat kami perhatikan dengan kebijakan kami konsisten mengimplementasikan CSR dari tahun 2008, dan sangat memperhatikandan menjalin hubungan sosial atau CSR dengan masyarakat sekitar dan mengusung konsep Tri Hita Karana dan ikut program Tri Hita Karana (THK) Bali dan sampai saat ini sudah memegang penghargaan Platinum Tourism Award".

Peran aktif PT Furama Villa \& Spa Ubud dalam kegiatan CSR dibuktikan dari program - program yang sudah di implementasikan sebelumnya, berikut program yang telah dilakukan sebagai berikut:

\begin{tabular}{cccc}
\hline No. & Kegiatan & Lokasi & Waktu \\
\hline 1 & $\begin{array}{c}\text { Pemberian dana support pada } \\
\text { setiap kegiatan seperti ulang } \\
\text { tahun STT, event lomba,dll } \\
\text { Pemeriksaan kesehatan gratis } \\
\text { lansia dan Pemberian sembako }\end{array}$ & Balai banjar bindu desa Mekar & $\begin{array}{c}\text { Setiap bulan Febru- } \\
\text { ari,satu tahun sekali }\end{array}$ \\
& Bagi lansia & Bhuana & Setiap bulan Maret \\
3 & Pemberian sumbangan terhadap & Tempat tinggal keluarga penyan- & Setiap bulan Mei \\
& penyandang cacat & dang & Setiap bulan Agustus \\
4 & Pemberian beasiswa sekolah & SDN 3 Mekar Bhuana & \\
& dasar yang berprestasi & & \\
\hline
\end{tabular}

Sumber: Dokumen PT Furama Villa and spa ubud, 27 November 2018

Bagi Masyarakat Banjar Bindu melihat program-program CSR yang diimplementasikan PT. Furama Villa \& Spa Ubud sangat bermanfaat bagi desa mereka dan masyarakat sekitar pun ikut berpartisipasi dalam programprogram CSR tersebut. PT Furama villa and spa ubud memiliki izin PT yang dikelola dari Furama internasional hotel Singapore.Kesuksesan PT Furama dalam menjalankan usahanya, memiliki kaitan erat dengan sikap peduli terhadap masyarakat dan lingkungan, dalam menciptakan keharmonisan tanpa menimbulkan konflik social, sesuai dengan jenis usaha yang dijalankan adalah memanjakan keindahan alam sekaligus mengeksporasi alam dan dapat menimbulkan dampak langsung maupun tidak langsung bagi masyarakat dan lingkungan perusahaan berdiri.
Dari uraian diatas penulis dapat berpendapat bahwa penerapan kegiatan CSR pada PT. Furama Villa and Spa ubud sangatlah bermanfaat bagi desa mekar bhuana khususnya Br. Bindu badung sebab masyarakat di sekitar perusahaan ikut berpartisipasi dan sangat mendukung program-program CSR. Dalam Perturan Pemerintah Republik Indonesia Nomor 47 tahun 2012 tentang tanggung jawab social dan lingkungan perseroan terbatas menyatakan secara jelas bahwa setiap Perseroan selaku subjek hukum mempunyai tanggung jawab social dan lingkungan, Peraturan pemerintah ini juga menyebutkan sebagaimana yang dimaksud pada Undang-undang Nomor 40 tahun 2007 pasal 74 ayat 1 tentang Tanggung jawab social UUPT yang menyatakan perseroan yang menjalankan usahanya dan atau berkaitan dengan sumber daya alam. Yang dimaksud 
dalam menjalankan kegiatan dibidang sumber daya alam adalah perseroan yang kegiatannya usahanya mengelola dan memanfaatkan sumber daya alam, yang dimaksud yang berkaitan dengan sumber daya alam adalah perseroan yang tidak mengelola sumber daya alam, tetapi kegiatan usahanya berdampak pada fungsi atau kemampuan sumber daya alam.

Substansi CSR Pada pasal 74 tersebut merupakan bagian yang tak dapat dipisahkan, sehingga tidak ada lagi alasan didalam dunia usaha yang bergerak dan atau berkaitan dengan sumber daya alam untuk tidak melaksanakan CSR, karena CSR merupakan kebijakan yang bersifat wajib (mandatory).

Implikasi Dalam Program CSR Pada PT. Furama Villa And Spa Ubud PT Furama Villa and Spa Ubud adalah perusahaan yang bergerak di bidang pariwisata yang sangat berpengaruh terhadap sosial dan lingkungan ataupun budaya yang berada di Desa mekar bhuana banjar bindu khususnya,menurut I Gusti ngurah Agus Chandrawan salah satu warga masyarakat yang tinggal di kawasan PT Furama Villa and spa mengaku bahwa kehadiran perusahaan tersebut justru menimbulkan dampak yang baik bagi warga tersebut, dikarenakan warga tersebut dapat bekerja di dalam perusahaan tersebut sekaligus ikut adil dalam melestarikan lingkungan dan budaya di sekitar PT Furama Villa and Spa Ubud.

Dampak dari Penerapan CSR Pada PT Furama Villa and Spa Ubud Menimbulkan 3 aspek yaitu:

\section{Dampak sosial}

PT Furama Villa and spa Ubud menjalin hubungan antara masyarakat, salah satunya keluarga yang diberikan sumbangan

Pihak PT Furama Villa and Spa ubud Memberikan perhatian penuh terhadap masyarakat sebagai contohnya memberikan karangan bunga terhadap perayaan ataupun kabar duka yang terjadi di lingkungan sekitar perusahaan

Kegiatan donor darah oleh karyawan atau masyarakat yang ingin menyumbangkan darahnya untuk disumbangkan kepada PMI untuk disumbangkan kepada yang membutuhkan

\section{Aspek ekonomi}

CSR tersebut Merupakan Komitmen dari perusahaan yang sangat diperhatikan pelaksanaannya oleh I ketut Sudiarta selaku
HRM untuk mengembangkan Pembangunan yang berkelanjutan sustainable developmentdengan cara meningkatkan perekonomian warga dengan menyerap kurang lebih 30\% tenaga kerja.

\section{Dampak lingkungan}

Pencemaran Lingkungan yang diakibatkan oleh limbah dari perusahaan yang kurang baik dikelola;

Kurang adanya Program Penghematan air, energy, dan lain-lain agar masyarakat tidak merasa dirugikan dengan adanya aktivitas perusahaan

Upaya yang dilakukan PT.Furama Villa and spa Ubud dengan komitmen Go-Green dengan menanamkan pohon dan memelihara Subak agar tetap terjaga dengan baik.

CSR bagi perusahaan PT. Furama Villa and spa Ubud dapat mempengaruhi perusahaan secara signifikan terkait dengan brand atau pemasaran maupun reputasi perusahaan selain kewajiban perusahaan untuk menjalankan peraturan yang berlaku, setiap kegiatan dalam perusahaan tentu akan menimbulkan kacamata bagi stakeholders perusahaan, CSR sangatlah penting dilakukan sebab akan membangun emosional positif terhadap masyarakat, sehingga citra perusahaan juga dapat terjaga ketika baik.

Perusahaan yang bergerak bergerak di dalam sektor pariwisata tentu dapat menimbulkan dampak negative maupun positif karena perkembangan pariwisata dan akomodasi pendukungnya yang pesat. Dampak positif dapat timbul dari beberapa aspek, diantaranya dari segi ekonomi antara lain menambah wisatawan sekaligus dapat membantu perekonomian yang ada di kabupaten badung khususnya, membuka dan menciptakan lapangan pekerjaan, aspek positif dari segi budaya antara lain dapat mengembangkan budaya agar diketahui diseluruh penjuru dunia, mendorong dan meningkatkan pendidikan yang lebih baik. Dari dampak positif didalam kegiatan oprasional tersebut tentu dapat menimbulkan dampak negative antara lain; seperti pergeseran sistem nilai dalam moral, etika kepercayaan dan pergaulan dalam masyarakat. Kegiatan oprasional perusahaan yang juga ingin mengembangkan usahanya secara berlebihan jika tidak dibatasi kegiatannya akan dapat menimbulkan pencemaran lingkungan yaitu pencemaran air, tanah, udara.

Dari uraian diatas penulis dapat 
menyimpulkan implikasi dalam program CSR PT. Furama Villa and spa ubud bahwa menimbulkan dampak positif yang sesuai dengan program CSR antara lain :

Pemberian beasiswa, dan penghargaan bagi siswa SD berupa alat belajar atau alat tulis, pemberian beasiswa ini diperuntukkan kepada siswa yang berprestasi agar diharapkan siswa lain lebih giat belajar.

Pemberian sumbangan bagi masyarakat yang mengalami cacat oleh perusahaan dengan diwakilkan oleh HRM Human resource manager I ketut sudiarta yang akan menimbulkan hubungan positif terhadap keluarga atau masyarakat penyandang cacat dengan perusahaan.

Pembangunan Fasilitas umum seperti lapangan voli yang pembangunannya dibantu oleh PT. Furama Villa and spa ubud dan juga sering diadakannnya Tournament yang dipanitai oleh STT. Dharma yowana

Pembuatan agrofarm dengan menata dan menanam Pohon dilakukan secara konsisteb sebab pembuatan agrofarm itu sendiru selain menjaga lingkungan tetap asri juga akan menjadi icon tersendiri bagi Perusahaan yang diperuntukkan untuk menyajakan keindahaan alam.

\section{Simpulan}

Adapun Simpulan yang dapat di kemukakan dari pemaparan rumusan masalah di atas adalah:

Penerapan CSR merupakan kewajiban suatu perusahaan selaku badan hukum yang tercantum pengaturannya pada pasal 74 ayat (1) dan peraturan pemerintah No. 47 tahun 2012 tentang tanggung jawab perusahaan terhadap social dan lingkungan,PT Furama Villa and spa ubud sudah membangun 4 sektor yakni sector pendidikan yaitu; pemberian beasiswa bagi sekolah dasar, sector social yaitu ; Pembagian sembako dan pemberian sumbangan bagi lansia dan penyandang cacat, sector ekonomi yaitu; menyerap tenaga kerja $30 \%$ dari masyarakat bidu, sector lingkungan lingkungan dan budaya yaiti; membuat event kebudayaan membuat agrofarm sekaligus dijadikan icon oleh perusahaan.

Implikasi dalam program CSR pada PT Furama Villa and spa Ubud tentu akan menimbulkan berbagai aspek antara lain: aspek social, ekonomi, lingkungan. Dampak social dari pelaksanaan CSR tsb yaitu menjalin emosi positif terhadap seluruh stakeholders dengan melakukan kegiatan donor darah, memberikan beasiswa dan sumbangan terhadap penyandang cacat dan sisiwa SD yang berprestasi, dari segi ekonomi perusahaan membantu perekonomian masyarakat dan kualitas hidup masyarakat di sekitar wilayah perusahaan, aspek lingkungan; yaitu kegiatan yang melestarikan subak dengan membuat agrofarm sekaligus menjadi icon oleh PT Furama Villa and Spa ubud.

\section{Daftar Pustaka}

Muhammad, A. (2002). Hukum Perusahaan Indonesia Bandung. Bandung: Citra Aditya Bakti.

Prawirokusumo, S. (2003). Prilaku Bisnis Modern Tinjauan Pada Etika Bisnis dan Tangggung Jawab Social. Jurnal Hukum Bisnis, 22(4).

Rudito, B., \& Famiola, M. (2013). Corporate Social Responsibility (Cetakan I). Bandung: Rekayasa.

Soemitro, R. (1993). Hukum Perseroan Terbatas, Yayasan, dan Wakaf. Bandung: PT. Eresco.

Wardiyanta. (2006). Penelitian Pariwisata (Cetakan I). Yogyakarta: Andi.

Ika Tresna Setiani, 2015, Mengupas CSR dalam Konsep dan Sejarah, http:// pride.co.id/2015/01/mengupas-csrdalam-konsep-dan-sejarah/ diakses 22 september 2018. 